\title{
LAS RELACIONES ENTRE LA ADMINISTRACION Y LOS ADMINISTRADOS
}

\author{
POY RAFAEL ANSON OLTART
}

Sumario: 1. Introducción. - 2. Comunicaciones ascendentes. - 3. Comunicaciones descendentes.-4. El derecho de petición.5. Las relaciones públicas y la eficacia de la Administración.-6. La colaboración del administrado en la actividad administrativa.

\section{Introducción}

En la Administración actual se viene observando un progresivo acercamiento al administrado, una tendencia a incorporarle como colaborador a los programas administrativos y a tener en cuenta como factores de la decisión administrativa sus necesidades, opiniones y sugerencias. Esta actitud ha sido consecuencia de una larga evolución político-social. En las épocas precedentes, los planos Administración y administrados se distinguen y diferencian nitidamente; domina la idea de una Administración que despacha expedientes sin que deba ser influida por el administrado.

Sin embargo, el sucesivo incremento de las necesidades de los 
DA-1964, núms. 078-079. RAFAEL ANSÓN OLIART. Las relaciones entre la Administración y los ...

particulares y la multiplicación de los servicios prestados por la Administración obliga a establecer las bases de una continua $\mathrm{y}$ necesaria colaboración. Por otra parte, en el terreno de los principios se acepta casi unánimemente que la Administración tan sólo debe prestar aquellos servicios que no pueden ser atendidos por la iniciativa privada, $y$, por supuesto, no debe realizar sola lo que pueda desarrollar con la cooperación de los administrados. Por último, la eficacia exige que la Administración actúe con la confianza del público. Lo contrario conduce a una actitud negativa por parte de éste, que se manifiesta en desinterés, ocultación y falseamiento, y que exige como reacción de la Administración la adopción de medidas inspectoras y correctivas.

Así, frente a la Administración «de expedientes» ha ido surgiendo poco a poco lo que pudiéramos llamar la Administración de programas, que se confeccionan teniendo en cuenta los datos y realidades del administrado. Frente a la ventanilla, símbolo de una Administración despreocupada y desvinculada de lo real, nace la oficina abierta, las informaciones públicas, las comisiones mixtas de funcionarios y administrados. Las relaciones públicas, entendidas como una actividad sistemática dirigida a aumentar el diálogo, la información y la participación entre el público y la Ađministración, consiguiendo así una colaboración más eficaz, han tomado carta de naturaleza en todas las administraciones.

En la Administración española no existe todavía una política coherente de relaciones públicas en sentido técnico. Sin embargo, de una u otra forma, aunque sin el carácter unitario y sistemático que seria de desear, existen organos administrativos que, unos por imperativos de la legislación y de las necesidades, y otros por sus atribuciones -oficinas de información, de prensa, de iniciativas y reclamaciones, etc-, atienden a especiales relaciones con el administrado.

El principio de colaboración entre el sector público y el privado aparece, referido tan sólo al procedimiento, en la Ley de Procedimiento Administrativo, de 17 de julio de 1958, en especial en sus artículos 33 y 34 , creando las Oficinas de información y las de iniciativas y reclamaciones, así como en los 87 y 130 , regulando las informaciones públicas. No obstante, es evidente que existen precedentes legislativos, sin tener que remontarse a los forzosamente extraídos del campo inagotable de lo que se ha llamado sla arqueología jurídico-administrativa», como el Decreto de 10 de octubre de. 1944 - famoso por su inoperancia y caido en desuso-, que esta- 
DA-1964, núms. 078-079. RAFAEL ANSÓN OLIART. L̇as relaciones entre la Administración y los ...

blecia, sobre todo en su articulo noveno, la posibilidad concreta de reclamaciones y quejas ante la Presidencia del Gobierno.

En general, nuestra normativa contiene los necesarios, aunque no suficientes, instrumentos para la realización de una política de relación con el administrado, al instituir una serie de actividades, órganos y procedimientos y al determinar múltiples medidas promoviendo la participación del administrado en la actividad administrativa. Tanto las comunicaciones ascendentes - del administrado a la Administración-como las descendentes - de la Administración al administrado-, asi como la colaboración del particular en las tareas administrativas, han experimentado un considerable desarrollo en los últimos tiempos como consecuencia de la política general de reforma administrativa que se ha llevado a cabo.

\section{Comunicaciones ascendentes}

El conocimiento de las necesidades, deseos y opiniones del administrado constituye un aspecto básico y quizá el más original de las relaciones públicas, que en este sentido se diferencian claramente de las técnicas usuales de información, propaganda y publicidad.

En este terreno se han creado determinados órganos que proporcionan directamente los instrumentos técnicos necesarios para conocer los deseos, mentalidad o intereses de los administrados y de la opinión pública en general:

- El Jnstituto Nacional de Estadística, reorganizado por orden del 26 de noviembre de 1962. Funciona por medio de Comisiones Asesoras, y en el ámbito periférico actúa a través de sus oficinas regionales, procurando la apoyatura estadística indispensable a toda investigación psicosocial.

- El Instituto Nacional de Psicología Aplicada y Psicotecnia - con sus delegaciones provinciales y locales-, estructurado según Decreto de 21 de febrero de 1963 , y cuyo funcionamiento se regula por el Reglamento de 30 de abril del mismo año, favorece el conocimiento de las motivaciones reales de los administrados y detecta sus actitudes básicas para los distintos problemas y la intensidad de las mismas.

- El Instituto de la Opinión Pública, creado por Decreto de 3 de enero de 1.963, para conocer, interpretar y valorar el estado de aquélla mediante los instrumentos adecuados de sondeo y encuesta. El preámbulo del Decreto justifica la creación del Instituto en «la necesidad de investigar los estados de la opinión pública con todas 
DA-1964, núms. 078-079. RAFAEL ANSÓN OLIART. Las relaciones entre la Administración y los ...

las garantías de las técnicas más depuradas, tanto de la psicologia social como de la sociología».

Con carácter especifico, y con la finalidad concreta de encauzar las inquletudes y sugerencias de los administrados, funcionan las oficinas de iniciativas y reclamaciones, creadas, en el aspecto de iniciativas, por el artículo 34 de la Ley de Procedimiento Administrativo, que desarrolla asimismo las antiguas posibilidades de reclamación establecidas por el Decreto ya citado de 10 de noviembre de 1944. Su misión es sestudiar y fomentar las iniciativas de los funcionarios y público, conducentes a la mejora de la estructura, funcionamiento y personal de los servicios administrativos y atender las quejas a que puedan dar lugar las tardanzas, desatenciones $u$ otras anomalías que se observen en el funcionamiento de los mismos». De acuerdo con 10 establecido en dicho articulo 34, se han constituído Oficinas de Iniciativas y Reclamaciones en todos los Ministerios civlles.

Son múltiples las disposiciones organizando tales Oflcinas. La primera, de aplicación general, es la Orden de la Presidencia del Gobierno de 5 de enero de 1959, en la que se especifican su organización, atribuciones y funcionamiento. Concretamente, el apartado 6) de dicha Orden determina que es competencia de las Oficinas de iniciativas y reclamaciones «recibir e impulsar aquellas iniciativas que se refieran a la mejora económica de los servicios, al mayor rendimlento del trabajo personal, a la supresión de trámites innecesarios, a la comodidad de los administrados y, en general, a cuanto se encamine a la mayor perfección de los servicios públicos»; el apartado 7) establece que conocerán igualmente de las quejas con ocasión de tardanzas o desatenciones, de las que resulte perjuicio o vejación para el reclamante, asi como de las que se deduzcan contra cualquier anomalia que se observe en el funcionamiento de los servicios administrativos. El apartado 8) ofrece la posibilidad de que las Oficinas propongan como iniciativas, para su ulterior tramitación, «las ideas o sugerencias que resulten de las reclamaciones presentadas».

Posteriormente, las Ordenes Ministeriales de 8 de enero de 1959, 24 de julio de 1961, 27 de febrero de 1962,17 de septiembre de 1962 y 21 de marzo de 1963, dictan normas relacionadas con las Oficinas de iniciativas y reclamaciones en el Ministerio de Asuntos Exteriores, Gobiernos Civiles, Dirección General de Correos y. Telecomunicación y Ministerios de la Gobernación y de Inđustria, respectivamente.

Las Oficinas de Iniciativas y Reclamaciones, sin embargo, desarrollan una actividad insuficiente. En lo que se reflere a las ini- 
DA-1964, núms. 078-079. RAFAEL ANSÓN OLIART. Las relaciones entre la Administración y los ...

ciativas, se observan dos deficiencias fundamentales: primero, la ausencia de un sistema satisfactorio de estímulos y premios, ya que tan sólo los Reglamentos del Ministerio de la Gobernación y del Ministerio de Obras Públicas prevén la utilización de este tipo de incentivos; segundo, la falta de una adecuada campaña de divulgación del interés y posibilidades de las iniciativas. En lo que respecta a las reclamaciones, el Jefe de la Oficina se encuentra en tal imposibilidad de invadir atribuciones ajenas, por lo que se limita normalmente a ser un mero receptor de las mismas para su elevación al Jefe del Departamento, con la consiguiente pérdida de agilidad y ejemplaridad. Por otra parte, no están previstas las atribuciones concretas del Servicio de Asesoramiento e Inspección del Procedimiento Administrativo, en orden al conocimiento de las reclamaciones que se produzcan ante la Presidencia, al amparo del artículo 34, 2 , de la Ley de Procedimiento Administrativo, aunque en el texto revisado de dicha Ley se prevé ya «la posibilidad de recabar de cualquier Departamento u Organismo los datos e informes que considere procedentes».

El procedimiento de queja establecido en el artículo 77 de la misma Ley de Procedimiento constituye también un medio importante de conocer la actitud de los administrados y los defectos de la Administración.

\section{Comunicaciones descendentes}

En cuanto a la información al administrado, la Ley de Procedimiento Administrativo distingue una información general sobre fines, competencia y funcionamiento de los órganos administrativos (artículo 33) y una información particular al interesado en relación con un determinado expediente administrativo (artículo 62), creando asimismo las Oficinas de Información correspondientes, que actualmente existen en todos los Ministerios Civiles.

La Orclen de 22 de octubre de 1958, por la que se dictan normas para el funcionamiento de las Oficinas de Información, especifica el cometido de las mismas, en su doble aspecto:

- Información general: comprenderá cuanto se refiere a la organización de los servicios, localización de dependencias, horarios de oficina, horas de visita, trámites de los diferentes tipos de expedientes, documentación que exijan, formas de gestión y, en general, cuantos informes sirvan de ilustración a quienes hayan de relacionarse con la Administración. Asimismo, prevé la posibilidad de que dicha información se realice a través de publicaciones ilustrativas, 
DA-1964, núms. 078-079. RAFAEL ANSÓN OLIART. Las relaciones entre la Administración y los ...

diagramas de procedimiento, organigramas o cualquier otro medio adecuado.

- Información de tipo particular: comprenderá el conocimiento en cualquier. momento del estado de tramitación de un expediente administrativo.

Esta misma orden aclara que «los informes que se emitan por las Oficinas de Información tendrán exclusivamente carácter ilustrativo e informativo para quienes lo soliciten».

En la Presidencia del Gobierno funciona el Centro de Información Administrativa, que cumple las funclones de impulso y coordinación y del cual dependen la Oficina de Información de la Presidencia, y los Servicios de Información Telefónica y de Información sobre Inversiones de Capital extranjero.

En otro sentido, las informaciones públicas pueden considerarse como una forma importantísima de información recíproca regulada, dentro de nuestra Ley de Procedimiento, en sus artículos 87 y 130, al establecer la posibilidad de acudir a tales informaciones cuando la naturaleza del procedimiento lo requiera o afecte a sectores profesionales, económicos o sociales, organizados corporativamente. Convendría, sin embargo, dar carácter general a las informaciones públicas previstas en el artículo 87 , que ahora sólo son posibles dentro de expedientes iniciados a instancia de parte (no obstante las informaciones previstas en otras normas).

\section{El derecho de petición}

Dentro de las relaciones entre Administración y administrados, constituye un apartado especial, por su extraordinaria importancia, la posibilidad reconocida en el artículo 70 de la Ley de Procedimiento Administrativo a toda persona natural o juridica de dirigir instancias $\mathrm{y}$ peticiones a las autoridades y organismos de la Administración; posibilidad ampliada por la Ley reguladora del Derecho de Petición, de 22 de diciembre de 1960, y normas complementarias.

El artículo $10^{\circ}$ de la Ley determina que «el derecho de petición es la facultad que corresponde a los españoles para dirigirse a los poderes públicos en solicitud de actos o decisiones sobre materia de su competencia. En relación con las Fuerzas e Institutos Armados, se establece que el ejercicio de dicho derecho «ha de coordinarse con el respeto a los principios de subordinación jerárquica y disciplina, que son base de los ejércitos».

Después de más de tres años de vigencia parece necesario refor- 
DA-1964, núms. 078-079. RAFAEL ANSÓN OLIART. Las relaciones entre la Administración y los ...

mar determinados artículos de la Ley de 22 de diciembre de 1960, así como crear Oficinas de gestión del derecho de petición en todos aquellos órganos ante.los que se presente un volumen considerable de peticiones.

\section{Las relaciones públicas y la eficacia de la Administración}

Quizá la labor más eficaz de Relaciones Públicas que puede plantearse está en el efectivo cumplimiento de las disposiciones y más concretamente de la Ley de Procedimiento administrativo. La aplicación de los principios de economia, celeridad, eficacia y el general de garantia, asi como la implantación de una organización racional de los servicios y de un procedimiento objetivo rápido y cómodo, constituirán el mejor sistema de lograr la participación de los administrados.

- La objetividad se introduce en la Ley a través de los requisitos de los actos administrativos, del régimen de instrucción (informes, prueba y audiencia), del de terminación y ejecución del procedimiento y del sistema de recursos.

- La celeridad se atiende por medio de la ordenación del procedimiento basada en los principios de impulsión de oficio y tramitaciones simultáneas, así como del régimen de términos y plazos.

- Y la comodidad por el establecimiento de las Oficinas de Información y de Iniciativas y Reclamaciones, por la obligación de localización y señalización de las dependencias, por el régimen de presentación y registro de solicitudes y por el horario de despacho al público.

Es evidente que toda politica de relaciones públicas debe estimular en los funcionarios el exacto cumplimiento de la Ley de Procedimiento Administrativo.

\section{La colaboración del administrado en la actividad administrativa}

La importancia de la colaboración entre la Administración y los administrados es cada vez mayor, sobre todo si tenemos en cuenta que la Administración está abandonando la vieja idea de una organización que despacha expedientes, para convertirse en una Administración de sentido empresarial, que debe elaborar programas y llevarlos a la práctica.

Es evidente que sin un clima previo de confianza y sin una re- 
DA-1964, núms. 078-079. RAFAEL ANSÓN OLIART. Las relaciones entre la Administración y los ...

lajación de la tensión existente y de la prevención del administrado hacia la burocracia, no puede esperarse una decidida colaboración, por muchas normas que se dictan regulándola.

sin embargo, existen ya una serie de ejemplos en este terreno que, aunque excesivamente parciales, establecen los cauces a través de los cuales pueda con el tiempo regularse con carácter general esta participación del administrado en las actividades administrativas.

La Ley de Montes de 8 de junio de 1957, es un ejemplo concreto de esta colaboración, al actualizar las antiguas modalidades de cooperación en la conservación de la riqueza forestal; asimismo, las Cámaras de Comercio y, más recientemente, las actuaciones conjuntas de las Leyes del Plan de Desarrollo Económico y Social y de Centros y Zonas de Interés Turístico, ambas de 28 de diciembre de 1963. En el Ministerio de Obras Públicas, las Juntas de Obras de Puertos, las Juntas de Tasas, las Confederaciones Hidrográficas y Comunidades de Regantes, la Mancomunidad de Canales del Taibilla, los Canales de Aragón e Isabel II, las Juntas Provinciales de Coordinación y Transporte, el Consejo Superior de Transportes, etcétera, son otros tantos ejemplos de esta colaboración.

Por otra parte, el fenómeno de la colectivización de las necesidades, consecuencia de la vida en grupo, ha inclinado a la Administración a reconocer y favorecer la constitución de Asociaciones de administrados, a través de los cuales puede hacerse efectiva la citada colaboración y, en ocasiones, su participación en la gestión de los servicios públicos.

Son manifestaciones de este fenómeno asociativo, en un ámbito general, las asociaciones de Padres de Alumnos de Enseñanza Media establecidas por Ley de 26 de febrero de 1953 (art. 70-72); las de campesinos, arrendatarios y pequeños propietarios, creadas por el Reglamento de Arrendamientos Rústicos, de 29 de abril de 1959, y las Asociaciones de Investigación Industrial, reguladas por el Decreto de 22 de septiembre de 1962. El de colaboración con la Administración viene a ser también uno de los fines de las Asociaciones de Cabezas de Familia, encuadradas en la Delegación Nacional de Asociaciones, cuyo estatuto general lleva fecha de 30 de junio de 1963.

En el ámbito concreto de la Administración local está reconocida la existencia de las Asociaciones de propietarios en los planes de urbanismo por Ley de 12 de mayo de 1956 (arts. 115 y sgs.), asi como la de las Asociaciones Administrativas, a que hacen referencia el Régimen de Carta para el Municipio de Barcelona, de 23 de mayo 
de 1960 , y la Ley especial para el Municiplo de Madrid, de 11 de julio de 1963.

$Y$ por fin, para no hacer interminable esta relación, basta con aludir a las múltiples Asociaciones con fines fiscales, tales como las de contribuyentes municipales, creadas por el Reglamento de 4 de agosto de 1952 (arts. 19 a 28); la Agrupación Sindical de Contribuyentes empresarios por rústica, creada por Orden de 14 de julio de 1961, y el réglmen de convenios de contribuyentes con la $\mathrm{Ha}-$ cienda Pública, introducido por la Ley de Reforma Tributaria de 26 de diciembre de 1957 y ampliada en la última Ley de Reforma Tributaria, de junio de 1964.

En resumen, pues, nuestra Administración se enfrenta en el presente con la decisión y el esfuerzo que supone unificar y dar coherencia a todas estas actividades de relaciones públicas, como factor que multiplica su eficacia en ese ldeal que constituye la participación plena del ciudadano en el quehacer social. 